\title{
O ESPAÇO DECADENTISTA EM “HISTÓRIA DE GENTE ALEGRE”, DE JOÃO DO RIO
}

\author{
Veridiana Mazon Barbosa da Silva (UFG/CAC) \\ Alexander Meireles da Silva (UFG/CAC)
}

Resumo: Este artigo tem como objetivo principal discutir a relação espaço $x$ personagens em um conto do escritor carioca João do Rio a partir de elementos do Decadentismo, abordando como uma das personagens da obra "História de gente alegre", publicado na coletânea Dentro da noite (1910) incorpora o espaço decadente e opressor e leva outra personagem, inocente e sem vícios, a perdição. Em segundo plano, a pesquisa busca também compreender a representação do homoerotismo feminino neste espaço opressor e corruptor do século passado, onde o que imperava era o preconceito e o moralismo.

Palavras-chave: Espaço, Decadentismo, Homoerotismo.

Abstract: This article aims to discuss the relation setting $x$ characters in a short story by the carioca writer João do Rio through elements of Decadentism, observing how one of the from the story "História de gente alegre", published in the book Dentro da noite (1910) incorporates the decadent and oppressive setting and leads another innocent and viceless to decay. In second level, the research also seeks to understand the representation of female homoeroticism in this oppressive and corruptive setting from the last century where prejudice and moralism were prevailing.

Keywords: Setting, Decadentism, Homoeroticism.

\section{CONSIDERAÇÕES INICIAIS}

Para que seja possível compreender determinada obra em sua totalidade, é imprescindível que se leve em conta o espaço e a configuração de suas características principais. O espaço é um elemento que precisa se ancorar nas demais categorias da narrativa, pois não se configura como um 
elemento isolado, como argumenta Barbieri (2009, p. 108) ao colocar que, "o espaço está intimamente ligado à ação, aos personagens, ao enredo, ao tempo e à perspectiva narrativa". Neste mesmo sentido, Lins ressalta que

não só espaço e tempo, quando nos debruçamos sobre a narrativa, são indissociáveis. A narrativa é um objeto compacto e inextrincável, todos os seus fios se enlaçam entre si e cada um reflete inúmeros outros. Pode-se, apesar de tudo, isolar artificialmente um dos seus aspectos e estudá-lo - não, compreendese, como se os demais aspectos inexistissem, mas projetando-o sobre eles: neste sentido, é viável aprofundar, numa obra literária, a compreensão do seu espaço ou do seu tempo, ou, de um modo mais exato, do tratamento concedido, aí, ao espaço ou ao tempo: que função desempenham, qual a sua importância e como os introduz o narrador. (LINS, 1976, p. 63-64)

Várias são as definições referentes ao espaço, que pode ser tanto físico, quanto psicológico, pode ser o espaço de nossos devaneios, o espaço da nossa memória, das nossas emoções e dos nossos sentimentos, pois, de acordo com Borges Filho (2009, p. 170), "cada ser percebe diferentemente o mesmo espaço. Dois seres colocados ao mesmo tempo no mesmo espaço terão opiniões diversas sobre ele." Tal situação é resultado das experiências de cada indivíduo, a memória 
é individual e, por isso, o mesmo espaço será percebido e lembrado de formas variadas por um grupo de pessoas em tais situações. Cada um associa aquele espaço em questão à determinada lembrança armazenada na sua memória e isso pode despertar nesse sujeito devaneios já esquecidos, mas que tal situação tem o poder de despertá-los novamente, por isso, é importante tratar o "espaço como instrumento de análise para a alma humana" (BACHELARD, 2008, p. 19).

Cada autor tem uma visão sobre o que seja o espaço, no caso de Santos (1997, p. 73), “o espaço é o resultado da soma e da síntese, sempre refeita, da paisagem com a sociedade através da espacialidade. A paisagem tem permanência e a espacialidade é um momento. A paisagem é coisa, a espacialização é funcional e o espaço é estrutural." Então, o espaço está em constante processo de mudança e adaptação dentro de uma paisagem, que é fixa e acabada. Como explica Barbieri (2009, p. 105), o espaço não tem a função de servir apenas como "pano de fundo" ou um cenário qualquer para o desenrolar da história, vai muito além disso, pois exerce o papel de um agente ativo dentro do enredo, podendo ser definido como um "articulador da história." A maneira como os personagens percebem o espaço é que proporciona ao leitor um maior entendimento 
sobre o andamento da história, fazendo ainda com que - leitor busque novas interpretações para a narrativa, ampliando então, as possibilidades de significação.

Neste sentido, percebe-se que através do espaço em que está inserido determinado personagem, somos capazes de definir a qual nível socioeconômico pertence, além disso, ficando evidente o porquê de certas atitudes e ações tomadas por ele. $\mathrm{O}$ espaço, o ambiente e o cenário auxiliam na interpretação de algumas ações, porém "a necessidade de criar categorias, tipologias para a apresentação do espaço na narrativa, logo se mostra infrutífera e mesmo desnecessária" (BARBIERI, 2009, p. 111), partindo da premissa que numa mesma narrativa podem ser encontradas várias possibilidades de significação inseridas nessa contextualização sobre espaço, demonstrando que

o modo pelo qual a personagem, por meio do narrador ou por si mesma, estabelece contato com o mundo que a cerca, mostra como ela o percebe, revela muitas das suas características e da sua personalidade que, sem isso, não seria possível observar. $O$ espaço pode também provocar estados e sensações naquele que o percebe, como este, pode atribuir sentidos e impressões para ele a partir de suas experiências. A percepção do espaço sempre passa pelo sujeito e por isso, será sempre subjetiva. (BARBIERI, 2009, p. 121) 
Ozíris Borges Filho (2008, p. 1-3) destaca algumas funções do espaço, deixando claro que dentro da narrativa podem ser elencados incontáveis propósitos, citando aqui, segundo ele, alguns dos mais importantes para se analisar um texto:

1-Caracterizar as personagens. De acordo com o nível socioeconômico e psicológico. 2- Influenciar as personagens. Notase que o espaço pode ser responsável por tal personagem agir de tal forma. 3- Situar a personagem. Nesse caso, a função do espaço se restringe apenas a informar o leitor onde o personagem se encontra. 4- Representar os sentimentos. Essa função diz respeito aos sentimentos dos personagens em relação ao cenário. 5- Estabelecer contraste. Pode não haver nenhuma relação entre sentimento e espaço. 6- Antecipar a narrativa. O narrador fornece indícios ou pistas ao leitor para que este seja capaz de desvendar o que ainda está por vir.

Diante dessas considerações, percebe-se como a discussão sobre espaço é importante na análise de uma narrativa, pois através dele compreendem-se determinadas ações e comportamentos, além de influenciar e modificar a personalidade das personagens, fazendo com que estas adotem tais posturas perante a certos fatos. O espaço, muitas vezes, corrompe e oprime o indivíduo, transformando-o em um produto do meio. Esta é a proposta discutida a seguir ao mostrar o espaço opressor na narrativa de João do Rio, demonstrando como o meio pode ser corruptor e como os 
grupos marginalizados necessitam conviver em um espaço fechado e alienado para que se sintam menos párias.

\section{JOÃO DO RIO E O ESPAÇO DECADENTE: A ALMA ENCANTADORA DAS RUAS}

O termo "Decadência" descreve um período da arte e da literatura que, comparado com a excelência de uma era anterior, está em declínio (CUDDON, 1992, p. 220). Ainda que o termo já tivesse sido usado para descrever o fim dos períodos Alexandrino (300-30 a. C.) e do Imperador Romano Augusto (14 a. D.), ele se consagrou nos tempos modernos na França para designar o movimento simbolista de meados a fim do século XIX. O movimento enfatizava a autonomia da arte, a necessidade pelo sensacionalismo, melodrama, egocentrismo, bizarro, artificial e pela posição autônoma do artista em relação à sociedade, particularmente a classe média burguesa.

Em termos estritamente literários, a noção de decadência apareceu pela primeira vez na França em 1834 no estudo do crítico Desiré Nisard no qual eram analisadas as semelhanças da poesia latina com a literatura romântica (LEVIN, 1996, p. 32). Mas foi com a coletânea de poemas Les Fleurs du mal (1857), do poeta Baudelaire, que a literatura decadentista encontrou o seu manifesto ganhando força pela sua 
influência sobre os artistas contrários ao establishment. Em 1884, o Decadentismo chega à prosa com a publicação de À rebours, do escritor francês Huysmans, considerado por Arthur Symons como o "breviário" do movimento. Nele, as ideias decadentistas ganham corpo no protagonista Des Esseintes, exemplificando a figura decadente que é consumida pela maladie fin de siècle. Ele devota sua energia, fortuna e inteligência à substituição do natural pelo artificial. Sua existência se resume à busca por sensações novas e bizarras. A transgressão entre o natural e o artificial também se faz presente na esfera dos limites e das convenções de gênero. A característica da transgressão sexual manifestada no corpo do homossexual, algo marcadamente ligado ao Decadentismo, também é observada em Oscar Wilde.

Assim como a cidade que tanto amou e tematizou na reportagem, na crônica e na ficção, João do Rio teve uma vida marcada pela intensidade do ambiente carioca da Belle Époque. Da mesma forma que o Rio de Janeiro dos salões e das vielas, dos five o'clock teas e das casas de ópio, ele também se apresentava como um ser cuja vida e obra desafiava definições simplistas e convenções estabelecidas. Mais do que a sua obra, porém, era a pessoa de João do Rio, pseudônimo do escritor e jornalista carioca João Paulo 
Alberto Coelho Barreto, que suscitava comentários extremos de admiradores e detratores contemporâneos. Vem destes últimos certamente as palavras do crítico Antônio Torres: "Paulo Barreto foi uma das criaturas mais vis, um dos caracteres mais baixos, uma das larvas mais nojentas que eu tenho conhecido" (Apud MARTINS,/s.n./, p.10). Todavia, como Brito Broca registrou, este retrato não era compartilhado pela maioria das pessoas do círculo do jornalista carioca João do Rio: "Os contemporâneos descrevem-no como uma criatura particularmente encantadora, amigo dos escritores novos, favorecendo os jovens de talento que apareciam pelas redações dos jornais" (BROCA, 1960, p. 110).

Como conciliar as duas imagens? Como explicar as imagens divergentes e aparentemente inconciliáveis? Certamente para se tentar analisar este personagem faz-se necessário aceitar a ideia de que sua identidade deve ser entendida justamente pela ambiência, contradição e paradoxo que fizeram dele um dos representantes mais fascinantes da também complexa Belle Époque carioca. Neste aspecto, um elemento fundamental ao se falar deste cronista dos costumes do Rio nos primeiros anos da República Velha é a Rua, local cujo fascínio exercido sobre o autor de A alma encantadora das ruas (1910) permitiria chamá-lo também de "João da Rua": 
Oh! SIM, as ruas têm alma. Há ruas honestas, ruas ambíguas, ruas sinistras, ruas nobres, delicadas, trágicas, depravadas, puras, infames, ruas sem história, ruas tão velhas que bastam para contar a evolução de uma cidade inteira, ruas guerreiras, revoltosas, medrosas, speenéticas, esnobes, ruas aristocráticas, ruas amorosas, ruas covardes, que ficam sem pinga de sangue... (RIO, 1987, p. 7)

A declaração de João do Rio não deixa dúvidas sobre a importância da rua em sua escrita. Esta entidade de vida própria, reflexo da alma ambígua do escritor-jornalista, é o lugar por onde passeiam de dia a dama da sociedade, o cavalheiro, as modern girls e os chamativos automóveis. É na noite, porém, que este local se revela plenamente na apresentação de sua atmosfera carregada de vício, medo e mistério. Portanto, percebe-se que o comportamento dos indivíduos se modifica e se adapta de acordo com a atmosfera da rua, tanto que durante o dia, as pessoas se preocupam em agir de determinada forma para não serem mal vistas e durante a noite, a busca pelo prazer e liberdade fazem com que os mesmos transeuntes se deixem levar por essa atmosfera misteriosa, daí vem tal fascínio de João do Rio por esse espaço de dubiedade. Como um exímio observador e estudioso da rua, este escritor carioca declara que: 
considerei a rua um ser vivo tão poderoso que consegue modificar 0 homem insensivelmente e fazê-lo o seu perpétuo escravo delirante, e mostrei mesmo que a rua é o motivo emocional da arte urbana mais forte e mais intenso. A rua tem ainda um valor de sangue e de sofrimento: criou um símbolo universal. Há ainda uma rua construída na imaginação e na dor, rua abjeta e má, detestável e detestada, cuja travessia se faz contra a nossa vontade, cujo trânsito é um doloroso arrastar pelo enxurro de uma cidade e de um povo. (RIO, 1997, p. 82)

Não à toa o título de seu principal livro de contos - Dentro da noite - anuncia o palco ideal para narrativas povoadas por jogadores, neuróticos, suicidas, sádicos, pervertidos, hiperistéricos e outros personagens desajustados. Falando sobre a importância desse elemento e do desejo de modernização urgente da época, Berman destaca: "Por toda a era de Haussmann e Baudelaire, entrando no século $X X$, essa fantasia urbana cristalizou-se em torno da rua, que emergiu como símbolo fundamental da vida urbana" (BERMAN, 1986, p. 300). Essa dubiedade da rua espelhava o homoerotismo de João do Rio.

Na maioria das obras desse escritor, o espaço ocupa um lugar de destaque, sendo um dos elementos mais representativos, transformadores e modificadores das 
ações dos personagens. Em "História de gente alegre", vemos uma personagem pura e sem vícios que é dominada e corrompida pelo meio, e passa a adotar uma postura que não pertence à sua personalidade e ao seu modo de ser. Desta forma, João do Rio se utiliza do espaço para abordar questões sociais, econômicas e culturais de uma sociedade preconceituosa, opressora e moralista, moldada em valores heterocêntricos, mostrando que, alinhado com os preceitos literários naturalistas do período, o meio é o principal agente transformador de personalidades e condutas consideradas como politicamente corretas. Os personagens desse autor carioca assumem o papel de provocar o leitor e desinquietá-lo, fazendo com que este questione até que ponto o meio depravado e pervertido de um ambiente hostil é capaz de influenciar e nortear a vida dos indivíduos criados por João do Rio, e que são espelhos de uma sociedade decadente, assim como afirma Julia O’Donnell (2008, p. 25), a literatura desse escritor é "parte constitutiva do mundo social e expressão de visões de mundo em torno das quais se conformavam determinados grupos sociais".

Essa postura está presente no conto "História de gente alegre", que mostra o posicionamento da sociedade brasileira 
do início de século $\mathrm{XX}$ em relação ao homossexualismo feminino e a questão de como o espaço opressor pode influenciar no comportamento das personagens.

\section{DENTRO DA NOITE: O ESPAÇO OPRESSOR EM “HISTÓRIA DE GENTE ALEGRE"}

O conto se inicia com a chegada do narrador anônimo a um restaurante onde ele se encontrará com o Barão André de Belfort, recorrente personagem da obra de João do Rio, se colocando muitas vezes como o alter ego literário do escritor na incorporação do dandismo decadentista. João do Rio descreve a casa onde ocorre toda a narrativa:

O terraço era admirável. A casa toda
parecia mesmo ali pousada à beira
dos horizontes sem fim como para
admirá-los, e a luz dos pavimentos
térreos, a iluminação dos salões de
cima contrastava violenta com o macio
esmaecer da tarde. Estávamos no Smart-
Club, estávamos ambos no terraço do
Smart-Club, esse maravilhoso terraço de
vila do estoril, dominando um lindo sítio
da praia do Russel. (RIO, 2002, p. 34)

Sendo um típico reduto frequentado pela burguesia do Rio da Belle Époque, esta casa se caracteriza pela presença de elementos e pessoas variadas tanto em nacionalidade como em classes sociais. Como observa o narrador: "Aquele ambiente de internacionalismo à parisiense cheio de rumor 
de risos, de gluglus de garrafas, de piadas, era uma excitação para a gente chique" (RIO, 2002, p. 36). Uma vez esperando seu jantar com o Barão, o jovem ouve uma conversa sobre o falecimento na noite anterior de Elsa d'Aragon, uma jovem de dezoito anos conhecida pelo narrador como uma das mais belas damas da noite. Em um mundo no qual os prostíbulos e cabarés são habitados por prostitutas e dançarinas desgastadas física e mentalmente, como a pequena prostituta de "A menina amarela" (1919), também de João do Rio, descrita como "um espectro de pesadelo, um ser irreal" (RIO, 2001, p. 125), Elsa se destacava como uma dama "do gênero nature. Ancas largas, pele sensível, animal sem vícios" (RIO, 2002, p. 39), segundo a descrição do Barão. O local era frequentado por todo tipo de gente, eram homens que procuravam por diversão, por jogatina e por mulheres de vida fácil ou de vida alegre, mulheres que se entregam aos vícios e aos excessos sem se importar com as consequências. Nessas casas onde ganhavam a vida esses seres corrompidos

havia franceses condecorados, de gestos vulgares, ingleses de smoking e parasita à lapela, americanos de casaca e também de brim branco com sapatos de jogar o football e o lawn-tennis, os elegantes cariocas com risos artificiais, risos postiços, gestos a contragosto do corpo, todos 
bonecos vítimas da diversão chantecler, os noceurs habituais, e os michês ricos ou jogadores, cuja primeira refeição deve ser o jantar/.../ (RIO, 2002, p. 35)

Porém, Elsa se via totalmente perdida em meio àquela atmosfera carregada de tristeza, angústia, dor e sofrimento causados por aquele ambiente opressor, permissivo e que suga as pessoas de todas as formas. O conceito de atmosfera está ligado ao espaço e de acordo com Barbieri (2009, p. 109) pode ser definido "como uma nova sensação que penetra o texto narrativo, um tom emocional que se infiltra pelo enredo, pelas personagens e pelos espaços." Assim era o espaço onde Elsa vivia, para ela a atmosfera daquele ambiente a angustiava e a entristecia, ela se sentia sufocada e invadida, pois "o meio é atrozmente artificial, a gargalhada, o champanhe, a pintura encobrem uma lamentável pobreza de sentimentos e sensações" (RIO, 2002, p. 38). Aqueles "paraísos artificiais" não ofereciam nada de concreto e seguro àquelas jovens sonhadoras e que buscavam um rumo para suas pobres e desgraçadas vidas, mas o que esses lugares proporcionavam era apenas a ilusão de uma vida fácil, as pessoas se divertiam somente naquele momento, as relações eram vazias, passageiras e artificiais. Ali, as cocottes tinham que ser as amantes que 
cometiam todos os tipos de loucuras e que cediam a todos os prazeres para satisfazer a todos os tipos de homem, por isso, "cinco anos de profissão acabam com a alma das galantes criaturinhas" (RIO, 2002, p. 38), ou seja, não passavam de mera mercadoria com prazo de validade.

Lins (1976, p. 99) afirma que "se há o espaço que nos fala sobre a personagem, há também o que lhe fala, o que influencia", como acontece com Elsa quando é atirada naquele ambiente hostil a ela e que representava um espaço vazio e corruptor, um local perigoso e que oferecia medo e insegurança:

A Elsa foi atirada subitamente numa pensão do Catete. Sabes o que é a vida em casas de tal espécie. Elas acordam para o almoço, em que aparecem vários homens ricos./.../ Nesses almoços discute-se a generosidade, a tolice ou a voracidade dos machos. A tarde é dada a um ou a dois./.../ À noite, o jantar em que é preciso fazer muito barulho, dançar entre cada serviço ou mesmo durante, dizer tolices./.../ O resto é ainda o homem até dormir. Nesse fantochismo lantejoulado há vários gêneros: o doidivana, o sério, o reservado, o nature, o romântico/.../ (RIO, 2002, p. 39)

Aqui, de fato, observa-se como Elsa é influenciada pelo espaço e aquela criatura pura, sem maldade e inocente vai 
se homogeneizando ao ambiente e se transformando em uma mulher devassa que se rende aos "vícios bizarros" de cheirar éter, tomar ópio e se picar com morfina. Enquanto isso, quem já havia se interessado pela corrompida Elsa é a interessante Elisa. E Elsa, ainda que fosse bela devido ao seu pouco tempo na noite, "com oito dias estava com os nervos esgarçados, estava excedida. Mesmo porque, desde a primeira hora olhava-a com seu olhar de morta a Elisa" (RIO, 2002, p. 39).

A partir desse ponto João do Rio introduz o elemento homoerótico do enredo na forma da lésbica Elisa, apresentada como "um tipo talvez normal nesse ambiente. Tem os cabelos cortados, usa eternamente um gorro de lontra. /.../ dizem-na com todos os vícios, desde o abuso do éter até o unissexualismo" (RIO, 2002, p. 39-40). Desde o seu surgimento, portanto, percebe-se que João constrói a visão de Elisa a partir dos estereótipos reservados aos homossexuais no Brasil do início do século XX e em especial às figuras femininas. Condizente com esta imagem, James Green esclarece que no homossexualismo feminino da Belle Époque,

As mulheres mais pobres eram obrigadas a adotar um gênero masculino como única opção para conquistar um espaço, [...] As mulheres masculinizadas, agressivas e 
bravas lograram impor um certo respeito na esfera pública, o que Ihes permitir sobreviver dentro de sua comunidade. (GREEN Apud GATTI, 2000, p. 6)

Após a descrição de Elisa, o Barão de Belfort, explicitando sua ligação literária com Lorde Henry Wotton, o personagem wildeano de O retrato de Dorian Gray (1891), explica a seu convidado como em uma ocasião encontrou Elsa "fora dos nervos" (RIO, 2002, p. 40) em uma casa noturna e à pedido dela a aconselhou a se entregar a "um excesso, um belo rapaz ou uma extravagância" (RIO, 2002, p. 41), induzindo a jovem a reparar no intenso olhar de paixão furiosa que Elisa, presente no mesmo local, lançava a ela. Inicialmente a bela dama é tomada pela repugnância à lésbica e a chama de demônio, "corri-a ontem do meu quarto. É um demônio" (RIO, 2002, p. 41), ao que o Barão devolve: "Mas você precisa de um demônio" (2002, p. 41). Semelhante ao diabo, Elisa é retratada em "História de gente alegre" como um monstro devasso e corruptor em oposição ao modelo feminino de beleza e delicadeza representado por Elsa. Vale destacar neste ponto que ambas as visões estão ancoradas nas ideias vigentes sobre a mulher na virada do século XIX para o XX.

Em uma época marcada pelo progresso das ciências, em diversas esferas da sociedade a figura feminina foi colocada 
no centro dos debates sobre o crescimento desordenado da população e a deterioração da higiene social. O controle sobre estes problemas, segundo estudiosos europeus do século XIX, passava pelo controle do corpo da mulher a partir da criação de um centro de estabilidade localizado no lar. Este espaço/ambiente deveria ser uma base para a harmonia e a castidade na qual a sociedade deveria se espelhar (ALTICK, 1973, p. 51-52). Nesta leitura, problemas como a criminalidade, a loucura e a alienação mental passaram a ser vistas como resultados de má-formação. Uma constituição degenerada ligaria o louco, o criminoso e o perverso. Este degenerado seria um indivíduo que se encontra em um estágio evolutivo inferior aos demais.

$\mathrm{Na}$ base desse debate se encontrava a influência da mulher enquanto reprodutora de novos membros sociais e a importância da ciência enquanto garantidora da geração de cidadãos saudáveis. Logo, duas vertentes se estabeleceram: uma situando o possível desregramento sexual, moral e social da mulher na sua constituição anatômica e fisiológica, e a outra destacando possíveis estigmas degenerativos que existiriam de forma latente no corpo feminino (NUNES, 2000, p. 93). Em ambos os casos, porém, prevalecia a crença de que a mulher era um ser de sexualidade bruta, algo 
expresso no seu ciclo menstrual. Daí que o feminino passa a ser associado às crianças, homens primitivos e alienados na condição de seres de segunda classe (ALTICK, 1973, p. 57). Essa associação se intensificou na virada do século XIX para o XX, quando a mulher se torna uma incógnita na forma de uma criatura que pode ser ao mesmo tempo uma santa ou um demônio, como bem mostra a representação literária presente em romances como Madame Bovary (1856), de Gustave Flaubert, O primo Basílio (1878), de Eça de Queiroz e $O$ despertar (1899), de Kate Chopin.

No conto de João do Rio, todavia, santa e demônio se perdem nos excessos da noite em busca de sensações e se tornam vítimas de seus desejos. Após ler uma carta enviada por sua mãe cujo conteúdo não é revelado ao leitor, Elsa decide aceitar o conselho do Barão e se entregar ao excesso: "E apareceu na ceia da pensão como uma louca, a mandar abrir champanhe por conta própria. Quando por volta de uma hora apareceu a figura de larva da Elisa, deu um pulo da cadeira, agarrou-lhe o pulso: 'Vem; tu hoje és minha!'” (RIO, 2002, p. 42). Após protagonizar cenas doentias de paixão em público nas quais sua repugnância era evidente, Elsa leva sua amante aos seus aposentos para continuarem seus excessos de luxúria regados à morfina. A casa permitia todo tipo de 
excesso e vício, pois a intenção daquele espaço decadente era promover a diversão a qualquer custo. Esse espaço decadente caracteriza-se pelo ar de mistério e fascínio, pelas experiências extravagantes e intensas, por proporcionar a exploração da imaginação sexual, pelo requinte dessas casas luxuosas e que cultuam a beleza acima de tudo e o interesse pela morbidez, que acaba sendo uma consequência dos vícios e da vida regada a prazeres artificiais, como é o caso de Elsa, uma jovem completamente influenciada por um ambiente infestado de permissividade.

Ao imaginar a cena no quarto envolvendo duas mulheres tão opostas, visto que "a sua morte pertence ao mistério do quarto [...]" (RIO, 2002, p. 41), pois este espaço da casa era permeado por uma atmosfera de mistério e requinte ao mesmo tempo: "O quarto, cheio de sombra, mostrava, em cima das poltronas, as sedas e os dessous de renda da Elsa. Um frasco de éter aberto, empestava o ambiente" (RIO, 2002, p. 43). O quarto, especificamente, representava um ambiente de prazer e medo, onde novas sensações eram vivenciadas e estas podiam ser ou não de dor e angústia, como também de satisfação e felicidade. A sombra simbolizava o medo de Elsa em não saber o que de fato ia acontecer, e como tudo ali à sua volta contribuía para sua transformação em uma mulher de vida fácil. Ela era apenas 
mais uma, e as sedas e rendas representavam o lado do luxo e do glamour, mas que para Elsa não tinha tanta importância se comparado ao sofrimento e à dor que essa personagem enfrentava. O Barão de Belfort ressalta a representação monstruosa reservada à homossexual Elisa: "como uma larva diabólica, o polvo loiro da roda iria arrancar um pouco de vida àquela linda criatura ardente, ainda com uns restos d'alma de mulher..." (RIO, 2002, p. 43).

Na sequência, já de madrugada, gritos de horror vindos do quarto de Elsa despertam os moradores de pensão e estes, ao adentrarem o quarto empestado pelo odor do éter, vislumbram o corpo de Elisa à beira da cama: "Os braços pendiam como dois tentáculos cortados" (RIO, 2002, p. 43). Na cama, morto, o corpo de Elsa, com as pernas em compasso, dá sinais de ter resistido aos avanços de Elisa, mas, tendo sido incapaz de resistir a força da lésbica, Elsa tem sua vida sugada em meio a um "suplício diabólico" (RIO, 2002, p. 44). Quanto a Elisa, a percepção da perda da amante tão desejada a leva ao desespero e a loucura: "Quando esta afinal satisfeita quis erguer-se, sentiuse presa pelos cabelos, tentou lutar, viu que a pobre era cadáver. E passou-se então para o monstro o momento do indizível terror [...] Elisa seguiu horas depois para o hospício, babando e estertorando" (RIO, 2002, p. 44). 
Depois disso, ainda houve uma preocupação em preservar aquele ambiente tão corruptor, devasso e permissivo, "foi uma complicação para afastar a polícia e impedir notícias nos jornais que desmoralizariam a casa" (RIO, 2002, p. 44).

\section{CONSIDERAÇÕES FINAIS}

O espaço é um elemento fundamental em toda narrativa, pois através dele, o leitor compreende com mais facilidade o personagem. O narrador se utiliza do espaço para influenciar o personagem, fazendo com que este surpreenda o leitor por meio de suas atitudes e comportamentos. Portanto, o espaço pode tanto influenciar, como contribuir para a caracterização, ou ainda aparecer somente com a função de situar o personagem na história. No caso do conto analisado, nota-se que João do Rio utilizou a personagem Elsa para demonstrar como o espaço transforma e corrompe uma conduta que até então parecia correta.

Quando Elsa passou a conviver naquele ambiente permissivo, devasso, permeado por vícios e excessos, ela logo se entregou e se deixou influenciar por aquele espaço topofóbico, segundo Bachelard (2008) é um espaço que provoca aversão e repulsa, é um espaço de clausura, desconforto e medo. Ao contrário da topofilia, que é o 
"espaço feliz" (2008, p. 19), o espaço que remete à proteção, segurança, estabilidade, aconchego e ao conforto.

Além disso, João do Rio demonstra através de sua obra imbuída do espírito finissecular que o preconceito contra o homossexualismo na primeira década do século $X X$, assim como se constata neste início do século XXI, pode fomentar monstros, que como tais, mostram na verdade nossos temores e inseguranças sobre um ser humano semelhante a nós.

\section{REFERÊNCIAS}

ALTICK, Richard D. "The weaker sex". In: ALTICK, Richard D. Victorian people and ideas: a companion for the modern reader of Victorian Literature. London: W. W. Norton \& Company, 1973, p. 50-59.

BACHELARD, Gaston. A poética do espaço. São Paulo: Martins Fontes, 2008. BARBIERI, Cláudia. (2009.) "Arquitetura Literária: sobre a composição do espaço narrativo". In: BORGES FILHO, O. e BARBOSA, S. (Org.). Poéticas do espaço literário. São Carlos, SP: Claraluz, 2009, p. 105-126

BERMAN, Marshall. Tudo que é sólido desmancha no ar: a aventura da modernidade. Trad. Carlos Moisés e Ana Loratti. São Paulo: Companhia das Letras, 1986.

BORGES FILHO, Ozíris. "Espaço e literatura: introdução à topoanálise". In: Anais do XI Congresso Internacional da Associação Brasileira de Literatura Comparada, 2008: São Paulo, SP - Tessituras, Interações, Convergências / Sandra Nitrini... et al. - São Paulo: ABRALIC, 2008. e-book.

. "Espaço, percepção e literatura". In.: BORGES FILHO, O. e BARBOSA, S. (Org.). Poéticas do espaço literário. São Carlos, SP: Claraluz, 2009, p. 167-189.

BROCA, Brito. A vida literária no Brasil: 1900. 2ed. Rio de Janeiro: José Olympio, 1960. 
CUDDON, J. A. "Decadence". In: CUDDON, J. A. Dictionary of Literary Terms and Literary Theory. 3ed. London: Penguin Books, 1992, p. 220-221. GATTI. José. Mais amor e mais tesão: história da homossexualidade no Brasil: José Gatti entrevista James Green. Ponto de vista. São Paulo: Unesp, ano 08, p. 149-166, $2^{\circ}$ semestre, 2000. Disponível em: http:// www.ieg.ufsc.br/admin/downloads/artigos/16112009-041036gatti.pdf. Acesso em: 26 out. 2011.

LEVIN, Orna Messer. As figurações do dândi: um estudo sobre a obra de João do Rio. Campinas: Editora da UNICAMP, 1996.

LINS, Osman. Lima Barreto e o espaço romanesco. São Paulo: Ática, 1976. MARTINS, Luís. "João do Rio: A vida, o homem, a obra." In: MARTINS, Luís. João do Rio: uma antologia. Rio de Janeiro: Instituto Nacional do Livro, /s.n./, p. 7-17.

NUNES, Silvia Alexim. $O$ corpo do diabo entre a cruz e a caldeirinha: um estudo sobre a mulher, o masoquismo e a feminilidade. Rio de Janeiro: Civilização Brasileira. (Coleção Sujeito e História), 2000.

O'DONNELL, Julia. De olho na rua: a cidade de João do Rio. Rio de Janeiro: Jorge Zahar, 2008.

RIO, João. A alma encantadora das ruas. Rio de Janeiro: Secretaria municipal de cultura. (Biblioteca Carioca; v.4), 1987.

. A alma encantadora das ruas. São Paulo: Companhia das Letras, 1997. . "A menina amarela". In: CUNHA, Helena Parente (Seleção). Melhores contos de João do Rio. 2ed. São Paulo: Global, 2001, p. 93-101. (Melhores contos; 15).

. Dentro da noite. São Paulo: Antiqua, 2002.

SANTOS, Milton. Paisagem e espaço. In: SANTOS, Milton. Metamorfoses do espaço habitado. São Paulo: Hucitec, 1997, p. 61-74.

Veridiana Mazon Barbosa da Silva é a autora deste artigo e Mestranda em Estudos da Linguagem pela Universidade Federal de Goiás (UFG), Campus Avançado de Catalão (CAC), sob a orientação do prof. Dr. Alexander Meireles 
da Silva, participante do Grupo de Pesquisa L.I.M.E.S., vinculada ao projeto de pesquisa "Fronteiras do Fantástico: Leituras da Fantasia, do Gótico, da Ficção Científica e do Realismo Mágico" e a dissertação "Sobre Monstros e Moléstias: o corpo homoerótico na ficção de João do Rio e Caio Fernando Abreu". Bolsista da Coordenação de Aperfeiçoamento de Pessoal de Nível Superior (CAPES).

Alexander Meireles da Silva é Doutor em Literatura Comparada pela Universidade Federal do Rio de Janeiro. Professor do Programa de PósGraduação Stricto Sensu em Estudos da Linguagem da UFG - Campus Catalão.

Recebido em 23 de abril de 2014. Aprovado em 18 de agosto de 2014. 